J Pediatr. 2012 June ; 160(6): 904-910. doi:10.1016/j.jpeds.2011.12.002.

\title{
$\beta$-cell dysfunction in Adolescents and Adults with Newly Diagnosed Type 2 Diabetes
}

\author{
Deborah A. Elder, MD' ${ }^{1}$, Patricia M. Herbers, MS $^{2}$, Tammy Weis ${ }^{1}$, Debra Standiford ${ }^{1}$, Jessica \\ G. Woo, PhD $^{2}$, and David A. D'Alessio, MD ${ }^{3}$ \\ ${ }^{1}$ Cincinnati Children's Hospital Medical Center Department of Pediatrics, Division of \\ Endocrinology, Cincinnati, Ohio, U.S.A. 45229 \\ ${ }^{2}$ Cincinnati Children's Hospital Medical Center Department of Pediatrics, Division of Biostatistics \\ and Epidemiology, Cincinnati, Ohio, U.S.A. 45229 \\ ${ }^{3}$ Department of Medicine, University of Cincinnati College of Medicine, and Cincinnati VAMC, \\ Cincinnati, OH, U.S.A 45267
}

\begin{abstract}
Objective-To compare $\beta$-cell function in adolescents and adults with newly diagnosed type 2 diabetes (T2DM).

Study design-Thirty-nine adolescents with T2DM, 38 age- and weight matched controls, and 19 adults with T2DM were studied. The adolescent diabetic subjects were divided based on whether they needed insulin to control their initial hyperglycemia. The primary outcome variable was the Disposition Index (DI), computed from the acute insulin response to glucose ( $\mathrm{AIR}_{\mathrm{g}}$ ) corrected for insulin sensitivity (1/HOMA-IR).
\end{abstract}

Results-DI was significantly reduced in all 3 diabetic groups (Control $n=3360$, adolescents with T2DM without insulin $n=630$, adolescents with T2DM with insulin $n=120$, adults with T2DM n=200; $<$ 0.001), and the adolescents with more severe hyperglycemia at diagnosis had lower DI than those with a more modest presentation $(\mathrm{p}<0.05)$.

Conclusion-At the time of diagnosis, adolescents with T2DM have significant $\beta$-cell dysfunction, comparable with newly diagnosed adults. Thus, severe $\beta$-cell impairment can develop within the first two decades of life and is likely to play a central role in the pathogenesis of T2DM in adolescents.

\section{Keywords}

adolescent T2DM; obesity; insulin secretion

\begin{abstract}
The incidence of type 2 diabetes mellitus (T2DM) in adolescents has increased significantly over the past 2 decades, coincident with increased rates of obesity (1-5). The pathophysiology and natural history of T2DM in adolescents is unclear and similarities to
\end{abstract}

(C) 2011 Mosby, Inc. All rights reserved.

Corresponding author: Deborah A. Elder, MD, Deborah.elder@cchmc.org, Cincinnati Children's Hospital Medical Center MLC 7012, 3333 Burnet Ave, Cincinnati, OH 45229, Phone 513.636.4744, Fax 513.636.7486.

Publisher's Disclaimer: This is a PDF file of an unedited manuscript that has been accepted for publication. As a service to our customers we are providing this early version of the manuscript. The manuscript will undergo copyediting, typesetting, and review of the resulting proof before it is published in its final citable form. Please note that during the production process errors may be discovered which could affect the content, and all legal disclaimers that apply to the journal pertain.

The authors declare no conflicts of interest. 
the pathogenesis of diabetes in adults have been assumed but not proven. Cross sectional evaluations of adolescents with established T2DM have demonstrated that nearly all have obesity and severe insulin resistance (6-8). In addition, impaired insulin secretion in response to oral and intravenous glucose is also typical $(9,10)$. Although some of the abnormalities of insulin secretion reported in adolescents with T2DM of several years duration are similar to those reported in diabetic adults $(6-8,11), \beta$-cell function in adolescents with recently-diagnosed T2DM has not been characterized.

Functional defects in insulin secretion are central to the development of T2DM in adults, and current evidence suggests that the capacity for insulin secretion declines gradually in the years before presentation, progressing eventually to a loss of normal glucose homeostasis (12-15). Adult subjects at risk for developing T2DM have detectable abnormalities of $\beta$-cell function, even though regulation of blood glucose remains normal $(16,17)$, suggesting either a constitutive islet cell defect or a process with a long evolution. Although the actual course of $\beta$-cell decline from normal glucose tolerance to T2DM has only been estimated (18), longitudinal studies in specific, high-risk subjects indicate that loss of insulin secretion sufficient for progression from normal glucose tolerance to diabetes occurs over a period of 4-6 years (19). Part of the loss of insulin secretory capacity may be due to a reduction in the number of $\beta$-cells because autopsy studies of adults with diabetes suggest a greater than $50 \%$ reduction in $\beta$-cell mass compared with normoglycemic adults (15). However, a reduction in the functional capacity of $\beta$ cells is also likely to contribute to the onset of diabetes (20).

The pathogenic model of T2DM in adults, with gradual decline in $\beta$-cell function and islet mass over years, is difficult to extrapolate to onset of disease in adolescence. In young people at risk for developing T2DM, the pre-morbid state is necessarily shorter and suggests a different rate of disease progression or a pathogenesis distinct from adult diabetes. One possibility is that $\beta$-cell dysfunction is not as severe in adolescents at the time they present with clinical disease. Several groups, including our own, have noted preservation of the acute insulin response to glucose $\left(\mathrm{AIR}_{\mathrm{g}}\right)$ in pediatric T2DM subjects, although this measure is impaired relative to the degree of insulin resistance $(6,8)$. By contrast, in adults with T2DM the $\mathrm{AIR}_{\mathrm{g}}$ is impaired even prior to the onset of diabetic hyperglycemia (13). One interpretation of these findings is that there is greater retention of $\beta$-cell capacity early in the course of T2DM in adolescents, consistent with a shorter period for disease development in younger patients. However, this conclusion is based only on indirect comparisons of $\beta$-cell impairment between adolescents and adults made across separate studies.

We hypothesized that compared with adults with new onset T2DM, adolescents with diabetes would have greater preservation of $\beta$-cell function. To test this hypothesis we measured $\beta$-cell responses to intravenous (IV) glucose and arginine in groups of adolescents at the time of presentation with T2DM, age- and weight-matched nondiabetic controls, and a group of recently diagnosed T2DM adults. The results of this study show that shortly after diagnosis, adolescents with T2DM have severe $\beta$-cell dysfunction that is comparable with the deficits seen in adult diabetes.

\section{Methods}

Thirty-nine adolescents newly diagnosed with T2DM (within $2.2 \pm 0.6 \mathrm{mos}$ ), and 41 nondiabetic obese subjects of similar age and weight (controls) were recruited from Cincinnati Children's Hospital Medical Center Hospital (CCHMC). Individuals with active concurrent illnesses, secondary diabetes, or pregnancy were excluded from the study. Three adolescent controls that subsequently developed T2DM in a longitudinal follow-up of the study were excluded from the baseline analysis to avoid misclassification, resulting in 38 
adolescent controls analyzed here. Nineteen adults with new-onset T2DM (Adult T2DM) were recruited from the Greater Cincinnati Area by newspaper advertisement. These subjects were within $6.5 \pm 3.0$ months of diagnosis and so were slightly later in their course than the diabetic adolescents. The different recruitment strategies reflect differences in diabetes management in our region, where children and adolescents are referred promptly to our Children's Hospital for treatment and education, and adults are diagnosed and treated by primary care physicians as outpatients.

At the time of diagnosis the adolescents with diabetes met American Diabetes Association criteria for diagnosis of T2DM (21). Twenty-two of these subjects (56\%) had been treated with insulin in the weeks before being studied to reverse uncontrolled hyperglycemia, but none had received insulin for at least 36 hours before testing. The decision to use insulin was the judgment of the clinician directing initial management of the patients and not based on standardized criteria. Nonetheless, this distinction in treatment separated the adolescent T2DM group by severity at onset and was used to subdivide the cohort after recruitment was completed but prior to analysis of outcomes: adolescents with T2DM initially receiving insulin $(n=22)$ and adolescent with T2DM not requiring insulin $(n=17)$. None of the adolescents with T2DM had a presentation consistent with ketoacidosis, none had markers of islet cell autoimmunity, using conventional clinical screening for glutamic acid decarboxylase-65, islet cell antibody 512 and insulin auto-antibody, and all had acanthosis nigricans at diagnosis. All adolescent subjects with T2DM were pubertal (Tanner IV or greater) based on examination by a pediatric endocrinologist. Of the adult diabetic subjects (32\%) were managed with diet alone, and the remainder with oral anti-diabetes medications; none was receiving insulin. All diabetic subjects were asked to withhold their oral diabetes medications for 3 days prior to study visits.

The obese control subjects were recruited from an obesity research program at CCHMC and had normal glucose tolerance as measured by a 75 g OGTT; thirteen percent $(5 / 38)$ were taking Metformin for management of insulin resistance. All the subjects started on metformin had documentation of normal glucose tolerance before starting treatment; metformin was discontinued for 3 days before $\beta$-cell function testing.

The study was approved by the CCHMC and University of Cincinnati Institutional Review Boards, and all subjects (or their parents, for those $<18$ years old) provided written informed consent or with written assent as appropriate (for patients $<18$ years old) to participate.

\section{$\beta$-cell function tests}

Consenting subjects reported to the General Clinical Research Center at CCHMC after an overnight fast for evaluation. Indwelling venous catheters were placed in both forearms for infusion of test substances and blood sampling; the arm designated for blood drawing was wrapped in a heating pad to arterialize venous blood (22). Subjects had sequential bolus administration of arginine ( 5 grams) and glucose ( 0.3 grams $/ \mathrm{kg}$, max dose 40 grams) with 50 minutes between infusions to allow equilibration of plasma glucose and islet hormones. Blood was sampled over 15 minutes following arginine and for 30 minutes after glucose to determine insulin responses. All blood samples were immediately placed on ice and centrifuged to separate plasma within an hour of collection. Plasma was separated and stored at $-80^{\circ} \mathrm{C}$ until processing.

\section{Biochemical measurements}

Plasma glucose measurements were made on whole blood using a YSI glucose analyzer (Yellow Springs Instrument, Yellow Springs, OH). Plasma insulin was measured by 
radioimmunoassay (RIA) as previously described (8). This assay uses a guinea pig antiinsulin serum that does not distinguish between proinsulin and fully processed insulin. Cpeptide and proinsulin were measured using commercial RIA kits (Millipore/Linco, Inc., St. Louis, MO). Hemoglobin $\mathrm{A}_{1 \mathrm{c}}\left(\mathrm{HbA}_{1 \mathrm{c}}\right)$ was measured using a modification of a highperformance-liquid-chromatography method using an Alliance 2690/2695 HPLC (Waters Corporation, Milford, MA) and a PolyCAT A column (PolyLC, Inc Columbia, MD) to separate the hemoglobin fractions by cation-exchange chromatography; $\mathrm{HbA}_{1 \mathrm{c}}$ results are reported as percent of total hemoglobin.

\section{Calculations and Statistical Analysis}

Fasting glucose and insulin levels were calculated as the mean of 3 values before arginine administration; baseline levels for the IV glucose portion of the study were the mean of two samples taken in the 10 minutes before infusion. The acute insulin responses to arginine $\left(\mathrm{AIR}_{\mathrm{ARG}}\right)$ and glucose $\left(\mathrm{AIR}_{\mathrm{g}}\right)$ were computed as the area under the curve over baseline of insulin concentrations at 2, 4, 6, 8, and 10 minutes after stimulus administration using Riemann sums based on the midpoint of each interval. The homeostatic model assessment of insulin resistance (HOMA-IR) was calculated using the online Oxford calculator (www.dtu.ox.ac.uk/homa). The disposition index (DI) was defined as the product of insulin secretion $\left(\mathrm{AIR}_{\mathrm{g}}\right.$ ) and insulin sensitivity (1/HOMA-IR). The glucose disappearance constant $\left(\mathrm{K}_{\mathrm{g}}\right)$ was calculated as the slope of the natural logarithm of blood glucose concentrations from 10-30 minutes after glucose infusion and is expressed as percent change per minute. Fasting proinsulin to insulin ratios (PI/I) were calculated for each subject before the glucose bolus by dividing the mean of two proinsulin measurements by the mean of two insulin measurements. Stimulated PI/I ratios were calculated in a similar manner using two postglucose infusion measurements of proinsulin and insulin.

All analysis were conducted considering four study groups, dividing the adolescent T2DM group based on initial management (e.g. insulin vs. no insulin), as described above. The decision to subdivide this group was made prior to analysis of outcomes. Data were analyzed using SAS v. 9.2 (SAS Institute, Cary, NC). Continuous baseline data were summarized as mean \pm standard error of the mean (SEM), and differences in baseline characteristics among groups were analyzed using ANOVA with Tukey-Kramer adjustments for multiple pairwise comparisons between groups. Categorical data were summarized as frequency counts with percentages, and differences between groups were analyzed using $\chi^{2}$ or Fisher's Exact Test, as appropriate.

Primary (DI) and secondary (AIR $\mathrm{g}, \mathrm{AIR}_{\mathrm{ARG}}$ ) outcomes were skewed, so analysis of metabolic testing outcomes were conducted using nonparametric methods. Comparisons of median values among the four groups were made using the Kruskal-Wallis test, with pairwise multiple comparisons controlled for using Tukey-Kramer adjustments. Potential differences in primary and secondary outcomes by metformin usage, race and sex were carefully considered, given the imbalance in these factors at enrollment. Sensitivity analysis revealed no significant effect of any of these factors (metformin, race, or sex) on any of the main outcomes within each study group (all adjusted p-values 20.05 ), indicating that imbalance in the prevalence of these factors across groups did not have a major impact on the reported group differences. Therefore, unadjusted comparisons among groups are presented. P-values $<0.05$ were considered significant.

\section{Results}

Table I presents the baseline characteristics of the 4 study groups. Across all groups BMI was comparable, and family history of diabetes did not differ. The adolescent diabetic and control groups were age-matched by design. There were no differences in Tanner staging 
among the adolescent groups. Adults with T2DM had a greater proportion of non-Hispanic white (NHW) participants than any of the adolescent groups, and was relatively overrepresented by women. Adults with T2DM were enrolled later after diagnosis than either adolescent T2DM group.

\section{Basal Metabolic Profile}

At the time of metabolic testing all 3 diabetic groups had moderate fasting hyperglycemia compared with the adolescent control group (Table II). The adolescents with T2DM receiving insulin also had a significantly higher $\mathrm{HbA} 1 \mathrm{c}$ than either of the other groups with T2DM, likely reflecting the glycemic severity at presentation. Adults with T2DM had lower fasting insulin and lower HOMA-IR than any of the adolescent groups, with adolescent controls exhibiting intermediate HOMA-IR values. Fasting proinsulin to insulin ratios (PI/I) were highest in adults with T2DM and lowest in adolescent controls and adolescents with T2DM receiving insulin; adolescents with T2DM not receiving insulin were intermediate.

\section{Stimulated $\beta$-cell function}

Starting from basal glucose levels at time 0 , the diabetic subjects had higher circulating glucose concentrations than the controls at each step after the arginine $\left(\mathrm{Mean}_{0-10 \mathrm{~min}}\right.$ : adolescent controls $89.5 \pm 1.0$, adolescents with T2DM not receiving insulin 118.2 \pm 7.5 , adolescents with T2DM receiving insulin $127.2 \pm 8.6$, adults with T2DM $149.3 \pm 13.3 \mathrm{mg}$ / dl) and glucose boluses ( $\mathrm{Mean}_{2-10}$ min: adolescent controls $258.1 \pm 5.6$, adolescents with T2DM not receiving insulin 284.1 \pm 9.2 , adolescents with T2DM receiving insulin $290.3 \pm$ 10.2 , adults with T2DM $322.8 \pm 21.5 \mathrm{mg} / \mathrm{dl})$. However, the increment in glucose above basal was not different among the groups (Table II).

$\mathrm{AIR}_{\mathrm{ARG}}$ was significantly reduced in adolescents with T2DM receiving insulin and adults with T2DM patients compared with adolescent control group ( $\mathrm{p}<0.001$; Table II). AIR $\mathrm{g}$ was significantly reduced in all groups with T2DM compared with adolescent controls (Figure, A and Table II). Furthermore, adolescents with T2DM not receiving insulin had higher AIR than adults with T2DM after glucose stimulation. Adolescents with T2DM receiving insulin exhibited $\mathrm{AIR}_{\mathrm{g}}$ values that were not significantly different from either of the other groups with T2DM. When AIR $_{\mathrm{g}}$ was corrected for insulin sensitivity, as the disposition index (DI), the $\beta$-cell responses to IV glucose in the three diabetic groups were significantly lower than the adolescent controls, but with adolescents with T2DM not receiving insulin were significantly higher than adolescents with T2DM receiving insulin (Figure, B and Table II).

Clearance of glucose after the glucose infusion (glucose disappearance constants $\left(\mathrm{K}_{\mathrm{g}}\right)$ was significantly and similarly diminished in all of the groups with T2DM, relative to adolescent controls (Table II). Also, after glucose stimulation all of the groups with T2DM had significantly higher PI/I ratios than adolescent controls.

\section{Discussion}

We directly compared insulin secretion in adolescents and adults with newly diagnosed T2DM. The results demonstrate that adolescents with T2DM have a marked impairment of insulin secretion at the time of diagnosis, even after a short course of treatment to correct hyperglycemia. Moreover, within our cohort of adolescent diabetic subjects there was a wide range of insulin secretory capacity and those with the most severe hyperglycemia at presentation, prompting insulin treatment at diagnosis, were more severely affected than those with more modest elevations of blood glucose. These findings do not support our hypothesis that adolescents with new onset T2DM have relatively greater preservation of $\beta$ cell function than adults newly diagnosed. In fact, our findings indicate that severe $\beta$-cell 
impairment is comparable with that of recently diagnosed adults with T2DM and a central feature of the presentation of T2DM in adolescence.

Defining new onset T2DM is inexact given the frequency of asymptomatic preclinical disease, and our cohort likely includes persons with a range of diabetes duration and severity. To arrive at a group representative of early T2DM, we recruited adult subjects within 1 year of diagnosis who were managed with diet or oral agents. Based on fasting glucose, $\mathrm{HbA}_{1 \mathrm{c}}$ and diabetes treatment, this group was generally comparable with the onehalf of our adolescent with diabetes not treated with insulin. Because the course of development of pediatric T2DM is unknown (23) defining adult and teenage cohorts at a comparable stage of disease involves some uncertainty. However, the limited evidence that does exist suggests that T2DM develops over years in adolescents as well as adults $(24,25)$. Thus, using recent diagnosis as the basis for aligning the adolescent and adult subjects for comparison is the most straight forward criteria now available and insures that all the subjects met common criteria for diabetes.

In the current study, the adolescents with T2DM are typical of the increasing population of adolescents with T2DM seen in our clinic (26). The majority of newly diagnosed adolescents in our region are admitted to the hospital for acute metabolic stabilization and education. Thus, most of the adolescents with T2DM were recruited as inpatients but studied 1-2 weeks after glucose stabilization when they returned for further diabetes education. Despite common ascertainment and initial stabilization, there was heterogeneity among this group of diabetic adolescents. One critical distinction was that approximately half were deemed to have severity of disease that merited insulin treatment from the outset; these subjects had a mean $\mathrm{HbA}_{1 \mathrm{c}}$ of $8.9 \pm 0.6 \%$. In those subjects in whom a clinical decision was made not to use insulin, but to start Metformin instead, the baseline $\mathrm{HbA}_{1 \mathrm{c}}$ was $6.5 \pm 0.2 \%$. Interestingly these two groups did not differ in age, race, BMI, or HOMA-IR, but had clearly distinct measures of insulin secretion. $\beta$-cell function was worse in the insulin treated subjects, even after a week or more of treatment for hyperglycemia, consistent with other reports of adults and adolescents in which diabetic subjects with more dramatic presentations had evidence of worse insulin secretion (27). The distinct presentations in our adolescent diabetic cohort suggest significant differences in either the stage of disease or rate of $\beta$-cell failure among teenagers developing this condition.

The adolescents with T2DM had insulin secretion that was generally similar to the adult diabetic subjects. Adolescents with T2DM receiving insulin had similarly low AIR $_{\mathrm{ARG}}$ as the adults with T2DM, and adolescents with T2DM without insulin had AIR ARG

comparable with the controls. However, AIR $_{\mathrm{g}}$ was significantly reduced in all the diabetic groups and this was especially apparent when corrected for insulin resistance as DI. Thus, although there was a range of $\beta$-cell function among the adolescent diabetic subjects that could be dichotomized based on presentation, overall these findings indicate that insulin secretion in adolescents with new onset T2DM is qualitatively and quantitatively similar to adults with early diabetes. This is somewhat surprising because the adults with T2DM almost certainly had a longer prediabetic period, and thus more time to develop $\beta$-cell dysfunction (27).

An increased percentage of plasma proinsulin is an established marker of $\beta$-cell dysfunction in adults with T2DM (28). In our groups of diabetic and nondiabetic subjects the adults had higher PI/I in fasting plasma than adolescent controls and adolescents with T2DM on insulin, with the adolescents with T2DM not on insulin intermediary between the other groups. This is similar to some $(6,11)$ but not all $(7)$ previous measures of these $\beta$-cell products in adolescent T2DM. However, following stimulation with IV glucose there was a higher proportion of proinsulin secreted among the diabetic compared with subjects without 
diabetes. Even though adults with T2DM tended to have the highest percentage of proinsulin in the $\beta$-cell response to glucose stimulation, this measure clearly separated the subjects with abnormal from those with normal insulin secretion, as has been consistently reported in previous studies of older subjects with diabetes (28).

There is little data currently available on the natural history of $\beta$-cell function in adolescent T2DM with which to estimate the time course for $\beta$-cell decline in adolescents. In one report there was a one year reduction in DI of $\sim 30 \%$ in pubertal Hispanic teens at high risk for T2DM (29). Cali et al published findings from a longitudinal study of obese young people with normal glucose tolerance (24). During 2-3 years of follow-up, 23\% of this cohort developed impaired glucose tolerance, coincident with a substantial reduction of insulin sensitivity. However, the subjects progressing to impaired glucose tolerance had relatively lower insulin responses at baseline and a decrease in $\beta$-cell function over time as reflected in a reduction of DI by $\sim 20 \%$ per year. Extrapolating from these estimated rates of DI decline, we speculate that $\beta$-cell failure in our 15 year old subjects likely began before age 12 . This time frame is consistent with a case report of a high-risk 10 year old girl progressing from insulin resistant but normal glucose tolerant to T2DM over 5 years (25).

There are several limitations to this study that must be considered in the interpretation of the results. First, even though the diabetic groups were representative of patients with early T2DM seen in our adolescent and adult diabetes clinics, the sample sizes are small, and demographically and clinically diverse, limiting our ability to identify specific factors that could contribute to our findings. In particular the imbalance of sex and race between the adolescent and adult groups has the potential for confounding. It is clear that in both adults and pediatric populations, African-Americans have higher insulin secretion than NHW individuals (30-33), and a similar but less pronounced effect has been described for female sex (34). We recognize that other studies have noted differences in insulin secretion among the races, and our study may have detected differences if the sample size was larger.

However, within our patient groups, the effects of race and sex were not significant, and analysis of the unadjusted numbers provides conservative estimates of between group differences such that we think it is unlikely that these variables affected our final conclusions in a meaningful way. Another variable that could have confounded the results were differences in the use of metformin. In the 5 metformin treated controls AIRg and DI were reduced relative to the others in this group, but metformin treatment had no effect on $\beta$-cell function within the diabetic groups. Therefore we also think it is unlikely that variable metformin use among the subjects affected the outcome of this study.

A second limitation is the potential influence of chronic hyperglycemia on $\beta$-cell function in the adolescents with T2DM. These subjects generally came to clinical attention based on symptoms of hyperglycemia, and 24 of these youths presented with blood glucose levels > $20 \mathrm{mmol} / \mathrm{l}$. However, all our adolescents with T2DM were treated immediately and not studied until 1-2 weeks later. Previous studies have demonstrated that even several days of insulin therapy is sufficient to reverse glucose toxicity and improve insulin secretion (35, 36). That this occurred in our subjects is suggested by the only moderate fasting hyperglycemia $(6.7 \pm 0.3 \mathrm{mmol} / \mathrm{l})$ that was present at the time of formal evaluation. A third limitation was the difference in ascertaining our adult and adolescent diabetic groups. Most adolescents in our area discovered to be hyperglycemic are referred promptly to our medical center for treatment, coming to immediate attention for treatment and education. Adults diagnosed with T2DM are treated less urgently and were recruited by advertisement. The different methods of recruitment may have enriched our adult cohort with less severely affected subjects. We attempted to mitigate this possibility by subdividing our adolescent diabetic cohort by severity of hyperglycemia at diagnosis. Our results demonstrate that the adults more closely resemble the more severely affected adolescents with T2DM, although it 
is important to note that the adolescents with T2DM did not differ from each other by any other characteristic. Finally, we used only short-term measures of the acute insulin response, and did not directly measure insulin sensitivity, but rather used the HOMA-IR estimate. We chose a shorter, less intense, protocol for $\beta$-cell function testing rather than traditional methods like the hyperglycemic clamp out of concern for the convenience of subjects just diagnosed with diabetes. The HOMA-IR estimate has recently been validated in adults with T2DM $(37,38)$, and even though lacking the precision of clamp and IVGTT techniques, is likely to be consistent across our groups of subjects.

In summary, adolescents with new onset T2DM have impaired insulin secretion in response to glucose and arginine, comparable with or worse than that of adults recently diagnosed with diabetes. We cannot determine from this cross sectional examination whether abnormalities of insulin secretion in adolescent diabetics are long-standing, with slow progression similar to the model for adult T2DM, or whether they develop more rapidly in the years to months before clinical presentation. The findings presented here demonstrate that adolescents with T2DM share key defects of insulin secretion with diabetic adults, although more research is necessary to determine whether the pathogenesis and natural history of $\beta$-cell dysfunction is shared across the age spectrum.

\section{Acknowledgments}

We thank Brianne Paxton, Kay Ellis and Clinton Elfers for their careful measurement of plasma hormones. We thank the nurses for their expertise with the protocols and their care of the research subjects, and are grateful to our study subjects for their participation.

Funded by National Center for Research Resources (NIH 5K23DK070775-03 to D.E. and R01DK57900 to D.D.), M01 RR 08084, and USPHS (grant \#UL1 RR026314).

\section{Abbreviations}

T2DM

HOMA-IR Homeostatic model assessment of insulin resistance

PI/I

$\mathbf{A I R}_{\mathrm{g}}$

AIR $_{\text {ARG }}$

BMI

$\mathbf{K}_{\mathbf{g}}$

$\mathrm{HbA}_{1 \mathrm{c}}$
Type 2 Diabetes Mellitus

Proinsulin to Insulin ratio

Acute insulin response to glucose

Acute insulin response to arginine

Body mass index

glucose disappearance constant

Glycosylated hemoglobin percentage

\section{REFERENCES}

1. Hannon TS, Rao G, Arslanian SA. Childhood obesity and type 2 diabetes mellitus. Pediatrics. 2005; 116(2):473-480. [PubMed: 16061606]

2. Bobo N, Evert A, Gallivan J, Imperatore G, Kelly J, Linder B, et al. An update on type 2 diabetes in youth from the National Diabetes Education Program. Pediatrics. 2004; 114(1):259-263. [PubMed: 15231940]

3. Duncan GE. Prevalence of diabetes and impaired fasting glucose levels among US adolescents: National Health and Nutrition Examination Survey, 1999-2002. Arch Pediatr Adolesc Med. 2006; 160(5):523-528. [PubMed: 16651496] 
4. Hedley AA, Ogden CL, Johnson CL, Carroll MD, Curtin LR, Flegal KM. Prevalence of overweight and obesity among US children, adolescents, and adults, 1999-2002. Jama. 2004; 291(23):28472850. [PubMed: 15199035]

5. Ogden CL, Carroll MD, Curtin LR, McDowell MA, Tabak CJ, Flegal KM. Prevalence of overweight and obesity in the United States, 1999-2004. Jama. 2006; 295(13):1549-1555. [PubMed: 16595758]

6. Weiss R, Caprio S, Trombetta M, Taksali SE, Tamborlane WV, Bonadonna R. Beta-cell function across the spectrum of glucose tolerance in obese youth. Diabetes. 2005; 54(6):1735-1743. [PubMed: 15919795]

7. Gungor N, Arslanian S. Progressive beta cell failure in type 2 diabetes mellitus of youth. J Pediatr. 2004; 144(5):656-659. [PubMed: 15127006]

8. Elder DA, Prigeon RL, Wadwa RP, Dolan LM, D'Alessio DA. Beta-cell function, insulin sensitivity, and glucose tolerance in obese diabetic and nondiabetic adolescents and young adults. $\mathrm{J}$ Clin Endocrinol Metab. 2006; 91(1):185-191. [PubMed: 16263830]

9. Burns N, Finucane FM, Hatunic M, Gilman M, Murphy M, Gasparro D, et al. Early-onset type 2 diabetes in obese white subjects is characterised by a marked defect in beta cell insulin secretion, severe insulin resistance and a lack of response to aerobic exercise training. Diabetologia. 2007; 50(7):1500-1508. [PubMed: 17393133]

10. Bacha F, Gungor N, Lee S, Arslanian SA. In vivo insulin sensitivity and secretion in obese youth: what are the differences between normal glucose tolerance, impaired glucose tolerance, and type 2 diabetes? Diabetes Care. 2009; 32(1):100-105. [PubMed: 18835946]

11. Elder D, Woo J, D'Alessio D. Impaired beta-cell sensitivity to glucose and maximal insulin secretory capacity in adolescents with type 2 diabetes. Pediatr Diabetes. 2009

12. Campbell K. Danger ahead: the emerging epidemic of type 2 diabetes in children. J Am Pharm Assoc (2003). 2003; 43(4):533-534. [PubMed: 12952319]

13. Pratley RE, Weyer C. The role of impaired early insulin secretion in the pathogenesis of Type II diabetes mellitus. Diabetologia. 2001; 44(8):929-945. [PubMed: 11484070]

14. Intensive blood-glucose control with sulphonylureas or insulin compared with conventional treatment and risk of complications in patients with type 2 diabetes (UKPDS 33). UK Prospective Diabetes Study (UKPDS) Group. Lancet. 1998; 352(9131):837-853. [PubMed: 9742976]

15. Levy JC. Beta-cell deterioration determines the onset and rate of progression of secondary dietary failure in type 2 diabetes mellitus: the 10-year follow-up of the Belfast Diet Study. Diabetic Medicine. 1998; 15(4):290-296. [PubMed: 9585393]

16. Pimenta W, Korytkowski M, Mitrakou A, Jenssen T, Yki-Jarvinen H, Evron W, et al. Pancreatic beta-cell dysfunction as the primary genetic lesion in NIDDM. Evidence from studies in normal glucose-tolerant individuals with a first-degree NIDDM relative. JAMA. 1995; 273(23):18551861. [PubMed: 7776502]

17. van Haeften TW, Dubbeldam S, Zonderland ML, Erkelens DW. Insulin secretion in normal glucose-tolerant relatives of type 2 diabetic subjects. Assessments using hyperglycemic glucose clamps and oral glucose tolerance tests. Diabetes Care. 1998; 21(2):278-282. [PubMed: 9539996]

18. Ferrannini E, Gastaldelli A, Miyazaki Y, Matsuda M, Mari A, DeFronzo RA. beta-Cell function in subjects spanning the range from normal glucose tolerance to overt diabetes: a new analysis. J Clin Endocrinol Metab. 2005; 90(1):493-500. [PubMed: 15483086]

19. Weyer C, Bogardus C, Mott DM, Pratley RE. The natural history of insulin secretory dysfunction and insulin resistance in the pathogenesis of type 2 diabetes mellitus. J Clin Invest. 1999; 104(6): 787-794. [PubMed: 10491414]

20. Ferrannini E. The stunned beta cell: a brief history. Cell Metab. 2010; 11(5):349-352. [PubMed: 20444416]

21. Standards of medical care in diabetes--2007. Diabetes Care. 2007; 30(Suppl 1):S4-S41. [PubMed: 17192377]

22. Kurpad AV, Khan K, Elia M. The effect of arterialization of blood by hand warming on the interpretation of forearm metabolic studies. Physiol Meas. 1994; 15(2):139-145. [PubMed: 8081192] 
23. Tfayli H, Arslanian S. Pathophysiology of type 2 diabetes mellitus in youth: the evolving chameleon. Arq Bras Endocrinol Metabol. 2009; 53(2):165-174. [PubMed: 19466209]

24. Cali AM, Man CD, Cobelli C, Dziura J, Seyal A, Shaw M, et al. Primary defects in beta-cell function further exacerbated by worsening of insulin resistance mark the development of impaired glucose tolerance in obese adolescents. Diabetes Care. 2009; 32(3):456-461. [PubMed: 19106382]

25. Saad R, Gungor N, Arslanian S. Progression from normal glucose tolerance to type 2 diabetes in a young girl: longitudinal changes in insulin sensitivity and secretion assessed by the clamp technique and surrogate estimates. Pediatr Diabetes. 2005; 6(2):95-99. [PubMed: 15963037]

26. Pinhas-Hamiel O, Dolan LM, Daniels SR, Standiford D, Khoury PR, Zeitler P. Increased incidence of non-insulin-dependent diabetes mellitus among adolescents. J Pediatr. 1996; 128(5 Pt 1):608_ 615. [PubMed: 8627431]

27. Colagiuri S, Cull CA, Holman RR. Are lower fasting plasma glucose levels at diagnosis of type 2 diabetes associated with improved outcomes?: U.K. prospective diabetes study 61. Diabetes Care. 2002; 25(8):1410-1417. [PubMed: 12145243]

28. Kahn SE. Clinical review 135: The importance of beta-cell failure in the development and progression of type 2 diabetes. J Clin Endocrinol Metab. 2001; 86(9):4047-4058. [PubMed: 11549624]

29. Goran MI, Shaibi GQ, Weigensberg MJ, Davis JN, Cruz ML. Deterioration of insulin sensitivity and beta-cell function in overweight Hispanic children during pubertal transition: a longitudinal assessment. Int J Pediatr Obes. 2006; 1(3):139-145. [PubMed: 17899631]

30. Rasouli N, Spencer HJ, Rashidi AA, Elbein SC. Impact of family history of diabetes and ethnicity on -cell function in obese, glucose-tolerant individuals. J Clin Endocrinol Metab. 2007; 92(12): 4656-4663. [PubMed: 17878257]

31. Hannon TS, Bacha F, Lin Y, Arslanian SA. Hyperinsulinemia in African-American adolescents compared with their American white peers despite similar insulin sensitivity: a reflection of upregulated beta-cell function? Diabetes Care. 2008; 31(7):1445-1447. [PubMed: 18417751]

32. Hales CN. The pathogenesis of NIDDM. Diabetologia. 1994; 37(Suppl 2):S162-S168. [PubMed: 7821732]

33. Haffner SM, Howard G, Mayer E, Bergman RN, Savage PJ, Rewers M, et al. Insulin sensitivity and acute insulin response in African-Americans, non-Hispanic whites, and Hispanics with NIDDM: the Insulin Resistance Atherosclerosis Study. Diabetes. 1997; 46(1):63-69. [PubMed: 8971083]

34. Basu R, Dalla Man C, Campioni M, Basu A, Klee G, Toffolo G, et al. Effects of age and sex on postprandial glucose metabolism: differences in glucose turnover, insulin secretion, insulin action, and hepatic insulin extraction. Diabetes. 2006; 55(7):2001-2014. [PubMed: 16804069]

35. Turner RC, McCarthy ST, Holman RR, Harris E. Beta-cell function improved by supplementing basal insulin secretion in mild diabetes. Br Med J. 1976; 1(6020):1252-1254. [PubMed: 1268654]

36. Vague P, Moulin JP. The defective glucose sensitivity of the B cell in non insulin dependent diabetes. Improvement after twenty hours of normoglycaemia. Metabolism. 1982; 31(2):139-142. [PubMed: 7043166]

37. Yokoyama H, Emoto M, Fujiwara S, Motoyama K, Morioka T, Komatsu M, et al. Quantitative insulin sensitivity check index and the reciprocal index of homeostasis model assessment in normal range weight and moderately obese type 2 diabetic patients. Diabetes Care. 2003; 26(8): 2426-2432. [PubMed: 12882874]

38. Sarafidis PA, Lasaridis AN, Nilsson PM, Pikilidou MI, Stafilas PC, Kanaki A, et al. Validity and reproducibility of HOMA-IR, 1/HOMA-IR, QUICKI and McAuley's indices in patients with hypertension and type II diabetes. J Hum Hypertens. 2007; 21(9):709-716. [PubMed: 17443211] 


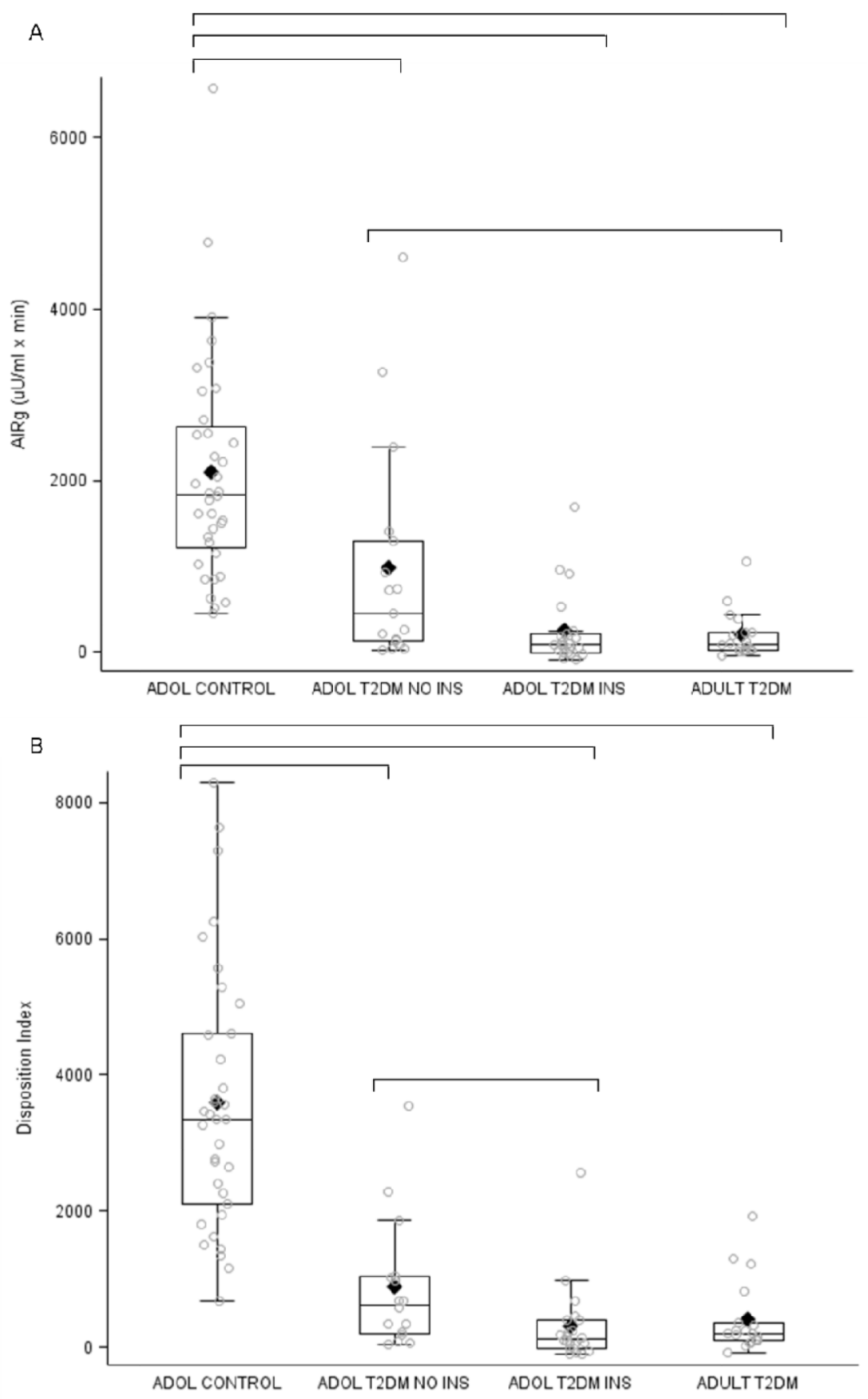

Figure.

$\mathrm{A}, \mathrm{AIR}_{\mathrm{g}}$ and $\mathrm{B}$, DI values for all subjects for each group. Open circles are drawn for each data point. Line within box is the median. Diamond is the mean. Top of box is the $75^{\text {th }}$ percentile; bottom of box is the $25^{\text {th }}$ percentile. Whiskers in box plots encompass all values within a $3 * I Q R$ distance from the $25^{\text {th }}$ and $75^{\text {th }}$ percentiles. Significant $p$-values $(p<0.05$ after Tukey-Kramer adjustment for multiple comparisons) are indicated by horizontal brackets. 
